\title{
The Optimal Time for Urinary Catheter Removal in Enhanced Recovery After Surgery (ERAS) Protocol After Laparoscopic Rectal Cancer Surgery: When and How?
}

\author{
Jaeim Lee \\ Department of Surgery, Uijeongbu St. Mary's Hospital, College of Medicine, The Catholic University of Korea, Seoul, Korea
}

\section{See Articles on Page 204-211}

After rectal cancer surgery, urinary catheterization is required to ensure bladder decompression perioperatively and avoid postoperative acute urinary retention [1]. However, urinary catheterization carries the risk of urinary tract infection and urethral injury and limits the patient's ambulation. For this reason, several studies have investigated the optimal time for urinary catheter removal after rectal surgery $[2,3]$.

The Enhanced Recovery After Surgery (ERAS) became standard care after colorectal surgery, and most of the surgeons follow the ERAS care program $[4,5]$. Within the ERAS program, there may be modifications depending on the patient's condition and the judgment of the care team, as is the removal of the urinary catheter. ERAS guidelines recommend urinary catheter removal on the first postoperative day whenever possible after rectal surgery. However, a suprapubic catheter is recommended for patients at high risk of prolonged postoperative urinary retention, i.e., males, preexisting prostatism, laparotomy, neoadjuvant therapy, large pelvic tumors, and abdominoperineal resection.

As recommended by the guidelines, postoperative 1-day removal may quickly reduce patient discomfort and reduce the possibility of urinary tract infection but may lead to urinary catheter reinsertion or ERAS protocol failure due to urinary retention or other complications.

Received: Jul 31, 2021 - Accepted: Aug 2, 2021

Correspondence to: Jaeim Lee, M.D.

Department of Surgery, Uijeongbu St. Mary's Hospital, College of Medicine, The Catholic University of Korea, 271 Cheonbo-ro, Uijeongbu 11765, Korea

Tel: +82-31-820-5020, Fax: +82-31-847-2717

E-mail: lji96@catholic.ac.kr

ORCID: https://orcid.org/0000-0002-4074-3904

(C) 2021 The Korean Society of Coloproctology

This is an open-access article distributed under the terms of the Creative Commons Attribution NonCommercial License (https://creativecommons.org/licenses/by-nc/4.0) which permits unrestricted noncommercial use, distribution, and reproduction in any medium, provided the original work is properly cited.
In this paper, the authors presented a compromised method within the ERAS program to remove urinary catheters within 72 hours after surgery while using alpha blockers [6]. Also, previous studies with low total mesorectal excision (TME) rates, including inflammatory disease or other benign conditions, are not suitable as a reference for optimal timing for urinary catheter removal after a rectal cancer operation. The present study is valuable as a study on the optimal urinary catheter removal time in a homogenous group with a high TME rate by targeting only rectal cancer patients. This protocol will serve as a good reference for the appropriate timing and method for urinary catheter removal for patients with rectal cancer surgery.

\section{CONFLICT OF INTEREST}

No potential conflict of interest relevant to this article was reported.

\section{REFERENCES}

1. Benoist S, Panis Y, Denet C, Mauvais F, Mariani P, Valleur P. Optimal duration of urinary drainage after rectal resection: a randomized controlled trial. Surgery 1999;125:135-41.

2. Kwaan MR, Lee JT, Rothenberger DA, Melton GB, Madoff RD. Early removal of urinary catheters after rectal surgery is associated with increased urinary retention. Dis Colon Rectum 2015;58:4015.

3. Schreiber A, Aydil E, Walschus U, Glitsch A, Patrzyk M, Heidecke $\mathrm{CD}$, et al. Early removal of urinary drainage in patients receiving epidural analgesia after colorectal surgery within an ERAS protocol is feasible. Langenbecks Arch Surg 2019;404:853-63.

4. Gustafsson UO, Scott MJ, Schwenk W, Demartines N, Roulin D, Francis N, et al. Guidelines for perioperative care in elective colonic surgery: Enhanced Recovery After Surgery (ERAS ${ }^{\circ}$ ) Society recommendations. Clin Nutr 2012;31:783-800.

5. Nygren J, Thacker J, Carli F, Fearon KC, Norderval S, Lobo DN, et al. Guidelines for perioperative care in elective rectal/pelvic 


\section{Coloproctology Jaeim Lee}

surgery: Enhanced Recovery After Surgery (ERAS $\left.{ }^{\circledast}\right)$ Society recommendations. Clin Nutr 2012;31:801-16.

6. Meillat H, Magallon C, Brun C, de Chaisemartin C, MoureauZabotto L, Bonnet J, et al. Systematic early urinary catheter re- moval integrated in the full Enhanced Recovery After Surgery (ERAS) protocol after laparoscopic mid to lower rectal cancer excision: a feasibility study. Ann Coloproctol 2021;37:204-11. 